\title{
Adoption of Improved Animal Husbandry Practices by Dairy Farmers of Doda District of Jammu and Kashmir, India
}

\author{
Sheikh Umair Minhaj ${ }^{1}$, S.A. Khandi ${ }^{1}$, Rayees Ahmed Bafanda ${ }^{1 *}$ and Bharat Bhushan ${ }^{2}$ \\ ${ }^{1}$ Division of Veterinary and Animal Husbandry Extension Education, F.V. Sc \& A.H. \\ SKUAST-J, R.S.PURA, JAMMU-181102, India \\ ${ }^{2}$ Faculty of Agriculture, SKUAST-J, Chatha, Jammu-180009, India \\ *Corresponding author
}

\begin{tabular}{|l|}
\hline Ke y w o r d s \\
Adoption, Improved \\
Animal Husbandry \\
Practices, Dairy \\
Farmers. \\
\hline Article Info \\
\hline $\begin{array}{l}\text { Accepted: } \\
\text { 19 October } 2017 \\
\text { Available Online: } \\
\text { 10 December } 2017\end{array}$
\end{tabular}

\section{Introduction}

Agriculture and agri-related activities form the backbone of the Indian economy. Despite a mere $17.62 \%$ contribution to gross domestic product (GDP), agriculture still provide livelihood support to about two third of the country's population (Central Statistical Organization (CSO), 2006). Livestock constitutes an important sub sector of Indian agriculture and contributes to about $4.36 \%$ of total GDP (CSO, 2006). The share of livestock sector in Agricultural Gross Domestic Product (AgGDP) increased from $14 \%$ in $1980-81$ to $23 \%$ in 1998 whereas the share of AgGDP in total GDP declined from $35 \%$ to $25 \%$ in the same period (Birthal, 2002). India possesses great potential in animal husbandry sector. The development of livestock sector is often considered as "pro- 
poor' and there is extensive delay between the livestock owner/ farmers first hear about the technologies and the time they adopt them. There is a considerable gap between the prevalent practices of dairy farmers and the available rearing technology, which poses a serious problem to the dairy industry (Rao et al., 1993).

There is wide a disparity in milk production between different states (rather districts) with $70 \%$ of total milk being produced by eight states only. The adoption behavior regarding dairy technology is area specific and is largely very low (Sirohi and Sirohi, 1997). The poor adoption of dairy technologies has been reported by many workers and in general not more than $30 \%$ of the available technologies have been adopted by the farmers in our country (Rao et al., 1993).

There is urgent need for productivity and production enhancement. Productivity and quality improvement depends on technology generation, Technology transfer, technology users and support mechanism, which need to be geared up. Farmers need to be updated on new technologies and scientific management practices of livestock production on regular basis. The productivity enhancement can be met by increasing the adoption of improved dairy practices.

Technological and management options are the only alternatives to accelerate the growth in productivity, which is currently low. Understanding the livestock management practices adopted by the farmers is necessary to identify the strength and weakness of the rearing systems and to formulate suitable intervention policies (Gupta et al., 2008). Hence, the present study was undertaken to document information regarding management practices adopted by the dairy farmers of the Doda district of Jammu and Kashmir.

\section{Materials and Methods}

The present study was conducted in Doda district of Jammu and Kashmir state. Doda district consists of seventeen blocks. Four blocks were randomly selected using simple lottery method. The selected blocks were Kastigarh, Bhagwah, Marmat and Ghat. After preparing a comprehensive list of villages of the selected blocks, two villages were selected randomly from each of the four selected blocks. Thus a total of eight villages were selected in all. Thereafter, fifteen respondents were selected randomly from each village. Thus a total 120 respondents were selected in all as the sample. Data was collected through well-structured interview schedule, personal interview from the respondents either at their farm or home after proper testing of schedule and using appropriate scales. The interview schedule was developed using the package of practices of neighboring universities as "universe of content" after proper consultation with the members of Faculty of Veterinary Science and Animal Husbandry, SKUAST-Jammu. The final schedule was divided into four broad areas namely management, feeding, breeding and health care for evaluation of adoption in their respective sections. The management component was further divided into general management and clean milk production practices Data were coded, classified, tabulated and analyzed using the software; Statistical Package for the Social Science (SPSS 16.0). The presentation of data was done to give pertinent, valid and reliable answer to the specific objectives. Frequencies, percentage, mean, standard deviation and mean percent score (MPS) were worked out for meaningful interpretation. The scale contained total 58 items, 15 items for general management practices, 11 items for clean milk production practices, 14 items for improved feeding practices and 9 items each for improved feeding practices and improved 
health care practices. Adoption index is the degree to which a respondent actually adopts practices. Against each of the practice, there were three columns representing "always adopted", "sometime adopted" and "never adopted". Each of them was given a score of 2 for scientifically "always adopted", 1 for "sometime adopted" and 0 for scientifically "not adopted" practices. The minimum and maximum scores respondents could get were 0 and 116. The adoption index was calculated through following formula:

Adoption index $=($ Obtained score $/$ Maximum score) X 100

\section{Results and Discussion}

Adoption level of respondents in different areas of improved animal husbandry practices

The adoption level of respondents regarding improved animal husbandry practices was also studied in four components i.e. management, feeding, breeding and healthcare. The management as a component of animal husbandry practice was further sub divided into two areas i.e. clean milk production and general management practices.

The scores obtained in the study are presented in the table 1. The overall adoption index of respondents was medium with the percent scores being 55.43. Thus it can be concluded that more than half of the recommended practices were adopted by the respondents. The medium level for extent of adoption of animal husbandry innovations is also reported by number of workers like Chugh et al., (1996), Fita et al., (2012), Jeelani et al., (2015), Kulkarni (1990), Mahipal and Kherde
(1989), Malik et al., (2014). Although the respondents do not vary considerably in their adoption levels in different components of animal husbandry, a closer look at the table 1 reveals that the adoption level of respondents was highest for improved health-care practices $(61.94 \%)$ followed by improved breeding practices $(61.15 \%)$. Lowest adoption scores were observed for general management practices $(45.83 \%)$ followed by improved feeding practices (54.25\%). Extent of adoption of recommended practices of animal husbandry, viz., management, feeding, breeding and health care practices were found to be $51.82,54.25,61.15$ and $61.94 \%$, respectively.

The findings of the study reveal that more emphasis on the general management practices and feeding practices. Thus it can be concluded that the adoption was highest for improved health-care practices and lowest for general management practices. The sector wise adoption of improved animal husbandry practices observed was in agreement with the findings of Mahipal and Kherde (1989) and Rathore et al., (2009).

Adoption index $=$ Obtained score $/$ Maximum score X 100

\section{Classification of the respondents based on adoption scores}

For appropriate analysis, the respondents were divided into three categories based on the adoption scores obtained (Table 2). As is evident from the table 2 majority of respondents $(66 \%)$ were having medium level of adoption followed by high adoption of animal husbandry practices (26\%). The respondents with the lowest adoption level constituted $8 \%$ of the total. 
Table.1 Adoption level of respondents in different areas of improved animal husbandry practices

\begin{tabular}{|l|l|l|l|l|l|}
\hline $\begin{array}{l}\text { Area of improved animal } \\
\text { husbandry practices }\end{array}$ & $\begin{array}{l}\text { Possible } \\
\text { Range }\end{array}$ & $\begin{array}{l}\text { Observed } \\
\text { Range }\end{array}$ & $\begin{array}{l}\text { Mean } \\
\text { Error }\end{array}$ & $\begin{array}{l}\text { Standard } \\
\text { Deviation }\end{array}$ & $\begin{array}{l}\text { Adoption } \\
\text { index }\end{array}$ \\
\hline General Management Practices & $0-30$ & $7-23$ & $13.75 \pm 0.35$ & 3.87 & 45.83 \\
\hline Clean Milk Production Practices & $0-22$ & $9-21$ & $13.20 \pm 0.26$ & 2.90 & 60.00 \\
\hline Total Management Practices & $0-52$ & $16-43$ & $26.95 \pm 0.58$ & 6.38 & 51.82 \\
\hline Improved Feeding Practices & $0-28$ & $8-23$ & $15.19 \pm 0.43$ & 4.73 & 54.25 \\
\hline Improved Breeding Practices & $0-18$ & $7-15$ & $11.01 \pm 0.21$ & 2.29 & 61.15 \\
\hline Improved Health-Care Practices & $0-18$ & $4-15$ & $11.15 \pm 0.23$ & 2.50 & 61.94 \\
\hline $\begin{array}{l}\text { Total of all Improved animal } \\
\text { husbandry Practices. }\end{array}$ & $0-116$ & $43-92$ & $64.30 \pm 1.32$ & 14.50 & 55.43 \\
\hline
\end{tabular}

Table.2 Classification of the respondents based on adoption scores

\begin{tabular}{|l|l|l|l|}
\hline Category & Low $(<\mathbf{4 9})$ & Medium $(\mathbf{5 0 - 7 8})$ & High $(>79)$ \\
\hline Frequency & 8 & 66 & 26 \\
\hline General Management Practices & $9.60 \pm 0.37$ & $12.74 \pm 0.36$ & $18.61 \pm 0.55$ \\
\hline Clean Milk Production Practices & $9.73 \pm 0.12$ & $25.44 \pm 0.56$ & $35.48 \pm 0.64$ \\
\hline Total Management Practices & $19.33 \pm 0.41$ & $25.44 \pm 0.56$ & $35.48 \pm 0.64$ \\
\hline Improved Feeding Practices & $10.00 \pm 0.17$ & $14.59 \pm 0.50$ & $21.22 \pm 0.18$ \\
\hline Improved Breeding Practices & $8.40 \pm 0.23$ & $10.51 \pm 0.22$ & $14.17 \pm 0.13$ \\
\hline Improved Health-Care Practices & $8.67 \pm 0.27$ & $10.44 \pm 0.26$ & $14.61 \pm 0.12$ \\
\hline $\begin{array}{l}\text { Total of all Improved animal } \\
\text { husbandry Practices. }\end{array}$ & $46.40 \pm 0.45$ & $60.98 \pm 1.15$ & $85.48 \pm 0.65$ \\
\hline Adoption index & 40.00 & 52.57 & 73.69 \\
\hline
\end{tabular}

Table 2 shows that overall adoption index for high, medium and low category was $73.96 \%$, $52.57 \%$ and $40 \%$ respectively. Thus the overall picture is encouraging. However, it can be suggested here that future extension efforts should lay emphasis on the respondents of low category so that they also reap the benefits of animal husbandry practices. It can also be advocated here that the cause of differential adoption of the three categories should be explored in future studies. This will pave way for better understanding the reasons of adoption or nonadoption of recommended practices and will certainly add to the effectiveness of future developmental efforts. The medium level for extent of adoption of animal husbandry innovations is also reported by number of workers like Chugh et al., (1996), Fita et al.,
(2012), Jeelani et al., (2015), Kulkarni (1990), Mahipal and Kherde (1989), Malik et al., (2014).

The study revealed that overall extent of adoption of improved animal husbandry practices in the study area was found to be only about $55.43 \%$. Majority of the respondents $(66 \%)$ had medium level of adoption. Extent of adoption of recommended practices of animal husbandry, viz., management, feeding, breeding and health care practices were found to be $51.82,54.25$, 61.15 and $61.94 \%$, respectively. Adoption of the respondents regarding improved health care practices was high, whereas adoption regarding improved management practices was low. Thus, extension agencies needs to intensively organize trainings, method 
demonstrations, exhibitions, group discussions, field tour etc. to increase adoption of improved animal husbandry practices at desire level with emphasize on learning rather than teaching.

\section{References}

Birthal, P.S. and Parthasarty, R.P. 2002. Economic Contribution of Livestock Subsector in India. In Proceeding of ICAR- ICRISAT Collabration Workshop held in January, 2002.

Chug, M. (1996). Exploratory study of dairy farm owned by ex-serviceman in Karnal District (Haryana). M.Sc., Thesis, National Dairy Research Institute, Karnal, Haryana (India). Central Statistical Organization, CSO, Govt. of India, Livestock Census 2006-2007.

Fita, L., Trivedi, M. M., and Tassew, B. 2012. Adoption of improved dairy husbandry practices and its relationship with the socio-economic characteristics of dairy farmers. In: Ada'a District Of Oromia State, Ethiopia. Journal of Agricultural Extension and Rural Development, 4(14): 392-395.

Gupta, D.C., Suresh, A and Mann S. 2008. Management practices and productivity status of cattle and buffaloes in Rajasthan. Indian J. Anim. Sci., 78 (7): 769-774

Jeelani, R., Khandi, S. A., Beig, M. Y.,
Bhadwal, M. S., and Kumar, P. 2015. Adoption of improved animal husbandry practices by Gujjars of Jammu And Kashmir. Indian Journal of Dairy Science, 68(3):287-291.

Kulkarni, V.V., Bhople, R.S. and Chede, P.N. 1990. Constraints in Adoption of Dairy Technologies by Farmers. Maharashtra Journal of Extension Education, 9: 137140.

Mahipal and Kherde, R.L. 1989. Correlates of Adoption Behaviour of Dairy Farmers. Maharashtra. Journal of Extension Education, 42(3): 434-439.

Malik, B.S. and Sohal, T.S. 2014. Field Adoption of Improved Animal Husbandry Practices. Indian Dairymen, 33(3): 25-29.

Rao, S.V.N., Kherde, R.L. and Sohal, T.S. 1993. Adoption of Dairy Innovations A Review. Indian Journal of Dairy Science, 46(9): 393-400.

Rathod, R. S., Singh, R. and Kachwaha, R. N. 2009. Adoption of recommended management practices and relationship between selected traits of the respondents. Indian Journal of Dairy Science, 62(4):327-334.

Sirohi, S. and Sirohi, S.K. 1997. Knowledge Level and Constraints of Adoption of Scientific Dairy Farming Practices among Farmers of Chinndwara District. Journal of Dairying, Food and Home Science, 16(1): 28-36.

\section{How to cite this article:}

Sheikh Umair Minhaj, S.A. Khandi, Rayees Ahmed Bafanda and Bharat Bhushan. 2017. Adoption of Improved Animal Husbandry Practices by Dairy Farmers of Doda District of Jammu and Kashmir, India. Int.J.Curr.Microbiol.App.Sci. 6(12): 2703-2707. doi: https://doi.org/10.20546/ijcmas.2017.612.313 